\title{
Correction to "Investigation into the Mechanism of Homo- and Heterodimerization of Angiotensin-Converting Enzyme"
}

The above article [Abrie JA, Moolman WJA, Cozier GE, Schwager SL, Acharya KR, and Sturrock ED (2018) Mol Pharmacol 93(4): 344-354; DOI: https://doi.org/10.1124/mol.117.110866] was published with an ASPET copyright line. Because the research was funded by the Research Councils UK Medical Research Council, the article should have been published under the CC BY Attribution 4.0 International license. The HTML and PDF versions of the article have been corrected.

The authors apologize for any inconvenience caused by this error. 